Laser and Particle Beams

cambridge.org/lpb

\section{Corrigendum}

Cite this article: Pisarczyk T et al (2018). Wavelength dependence of laser plasma interaction related to shock ignition approach - CORRIGENDUM. Laser and Particle Beams 36 514. https://doi.org/10.1017/

S0263034619000016

\title{
Wavelength dependence of laser plasma interaction related to shock ignition approach - CORRIGENDUM
}

\author{
T. Pisarczyk ${ }^{1}$, S.Yu. Gus'kov'2,3, R. Dudzak ${ }^{4,5}$, O. Renner,4, D. Batani ${ }^{3,6}$, \\ T. Chodukowski ${ }^{1}$, Z. Rusiniak ${ }^{1}$, J. Dostal ${ }^{5,4}$, N.N. Demchenko ${ }^{2}$, M. Rosinski ${ }^{1}$, \\ P. Parys ${ }^{1}$, M. Smid ${ }^{4}$, Ph. Korneev ${ }^{2,3}$, E. Krousky ${ }^{4,5}$, S. Borodziuk ${ }^{1}$, J. Badziak ${ }^{1}$, \\ L. Antonelli ${ }^{7}$, L.A. Gizzi ${ }^{8}$, G. Cristoforetti ${ }^{8}$, P. Koester ${ }^{8}$, Y. Maheut ${ }^{6}$, L. Volpe ${ }^{9,10}$, \\ F. Baffigi ${ }^{8}$, T. Levato ${ }^{11}$, J. Skala ${ }^{5}$, A. Zaras-Szydlowska ${ }^{1}$, J. Trela ${ }^{12}$, D. Mancelli, \\ J. Ullschmied ${ }^{4,5}$, M. Pfeifer ${ }^{4,5}$, L. Juha ${ }^{4,5}$, M. Krus ${ }^{4,5}$, J. Hrebicek ${ }^{4,5}$, T. Medrik ${ }^{4,5}$, \\ K. Jungwirth ${ }^{4}$, M. Krupka ${ }^{5,13}$ and P. Pisarczyk ${ }^{14}$
}

${ }^{1}$ Institute of Plasma Physics and Laser Microfusion, 01-497 Warsaw, Poland; ${ }^{2} \mathrm{P}$. N. Lebedev Physical Institute of RAS, 119991 Moscow, Russian Federation; ${ }^{3}$ National Research Nuclear University MEPhl, 115409 Moscow, Russian Federation; ${ }^{4}$ Institute of Physics, Czech Academy of Sciences, 18221 Prague, Czech Republic; ${ }^{5}$ Institute of Plasma Physics, Czech Academy of Sciences, 18200 Prague, Czech Republic; ${ }^{6}$ Universite Bordeaux, CNRS, CEA, CELIA, Talence, France; ${ }^{7}$ York Plasma Institute, University of York, York, UK; ${ }^{8}$ National Institute of Optics, CNR, Pisa, Italy; ${ }^{9}$ Universidad de Salamanca, 37008 Salamanca, Spain; ${ }^{10}$ Centro de Láseres Pulsados (CLPU), 37185 Villamayor, Salamanca, Spain; ${ }^{11}$ Institute of Physics of the ASCR, ELI Beamlines Project; ${ }^{12}$ Universita di Roma La Sapienza, Italy; ${ }^{13}$ Faculty of Nuclear Sciences and Physical Engineering, CTU in Prague, 11519 Prague, Czech Republic and ${ }^{14}$ Warsaw University of Technology, ICS, 00-661 Warsaw, Poland

doi: 10.1017/S0263034618000447, Published online by Cambridge University Press, 16 November 2018.

In the original publication of this article, multiple affiliations were missing and several authors were not properly linked to their affiliations. The above list consists of the correct affiliations, and the original article has been updated to reflect the changes.

The authors apologize for the errors.

\section{Reference}

Pisarczyk T, Gus'kov SY, Dudzak R, Renner O, Batani D, Chodukowski T, Rusiniak Z, Dostal J, Demchenko NN, Rosinski M, Parys P, Smid M, Korneev Ph, Krousky E, Borodziuk S, Badziak J, Antonelli L, Gizzi LA, Cristoforetti G, Koester P, Maheut Y, Volpe L, Baffigi F, Levato T, Skala J, Zaras-Szydlowska A, Trela J, Mancelli D, Ullschmied J, Pfeifer M, Juha L, Krus M, Hrebicek J, Medrik T, Jungwirth K, Krupka M and Pisarczyk P (2018) Wavelength dependence of laser plasma interaction related to shock ignition approach. Laser and Particle Beams, doi: 10.1017/S0263034618000447. 